\title{
The Two-warehouse Material Location Selection Problem
}

\begin{abstract}
Companies often require additional warehouse space due to increased demand and often the option of building a warehouse is not feasible due to a high investment cost. As a result excess inventory that cannot be stored in owned warehouses is transferred to third-party warehouses for which the company pays rent, as well as incurs labor and transportation costs for storing items and moving items back to the production site. In this situation, the company ends up with two warehouses - owned and rented. This research introduces the material location selection problem that allocates materials to these two warehouses while minimizing the total storage and transportation costs. Four material location models/policies, each with different decision restrictions, are proposed to solve the problem from different material handling perspectives. The four models are analyzed and contrasted with each other based on data derived from a real industrial scenario. The case results show a cost savings opportunity between $20 \%$ - $40 \%$ due to reassigning materials between the rented and owned warehouses.
\end{abstract}

Keywords: Material location selection; Warehouse management; Owned/Rented warehouses; Third Party Logistics

\section{Introduction}

In a typical supply chain network items are transformed into final products by being processed sequentially at multiple locations. The warehouse function is an important part of a typical supply chain network. Over the past decade, this function has been outsourced not only to reduce cost (i.e. operational and fixed asset) and simplify operations, but also to allow companies to focus on their core business (Rao \& Young, 1994; Langley \& Capgemini, 2014, 2015; Phillips, 2015). Warehousing generally takes the form of a distribution center and usually follows manufacturing processes. In contrast with a distribution center, a production warehouse is used to store production materials (i.e. each of which contains multiple items) and is often assumed to be integrated as local storage within the manufacturing process. This assumption is valid as long as each production site owns an onsite production warehouse. This is typically the case in order to immediately respond to changes in production demand and to keep production running smoothly.

One limitation of using an owned warehouse is that it has finite storage capacity, so in the case where the capacity limit is reached the manufacturer may resort to a third party warehouse where they are charged for the storage space used and the transportation cost to deliver items to the production site. Additional storage space may be required as both the production volume and variety increases, causing an increase in raw material and product volumes. In addition, material supplies may be purchased in relatively large quantities in order to take the advantage of scale economies (Hsieh et al., 2008; Liang \& Zhou, 2011). This paper deals with the material location 
selection decision in which materials are assigned where to be received and stored between two different warehouses (owned and rented) after purchase decisions have been made.

The rented warehouse is also often referred to as an overflow warehouse, off-site warehouse, contract warehouse or third-party warehouse. Their meanings can be slightly different with respect to potential additional services provided by each type of warehouse, apart from providing item storage. Nevertheless, the main purpose of renting a warehouse remains the same, which is to provide additional storage space when the owned warehouse reaches its capacity limit and the cost of expanding the owned warehouse requires a high cost investment that is not justifiable based on a long-term strategic evaluation.

Figure 1 shows the flow of material items/pallets within the manufacturing stage of a supply chain when the manufacturer rents a warehouse for excess production material inventory. As pallets are distributed between the two warehouses (rented warehouse and production warehouse), moving them from the rented warehouse to the production site results in a transportation cost, in addition to the space rental cost. While pallets of different materials are demanded with different rates, storing fast moving pallets (relatively high demand) in the rented warehouse means frequent dispatching of the pallets from the warehouse to the production site. Depending on how long each pallet is stored in the rented warehouse, the transportation cost per unit may be higher than the storage space rental cost.

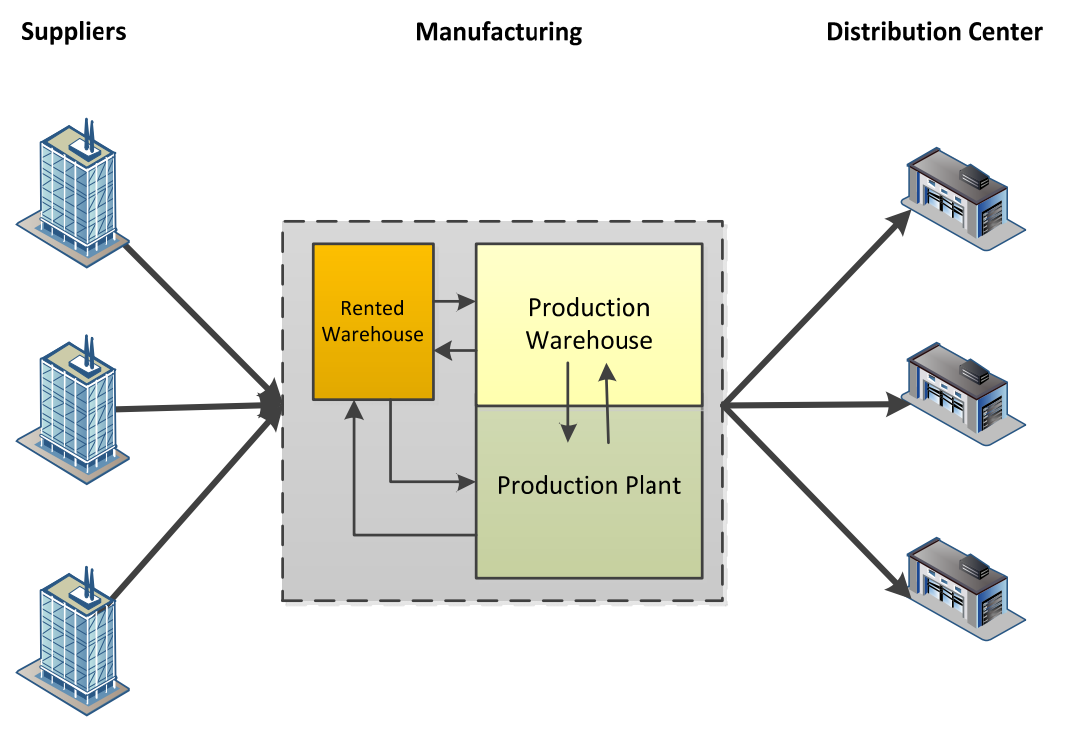

Figure 1 Manufacturing Entity with Rented Warehouse

In order to understand the importance of how to allocate materials between the two warehouses, consider the simple example illustrated in Figure 2, which shows three sample inventories of materials $\mathrm{A}, \mathrm{B}$ and $\mathrm{C}$ and their replenishment cycles. If the production warehouse can hold up to 20 pallets, choosing material A to be stored onsite (i.e. at the production warehouse) and the other materials to be stored offsite (i.e. at the rented warehouse) results in 100 pallet transshipments per month from the rented warehouse to the production plant. In 
contrast, choosing material $\mathrm{C}$ to be stored onsite results in only 60 transshipments of material A and $\mathrm{B}$ from the rented warehouse to the production plant. The aim of this research is to develop material location selection policies to assign items/pallets or materials to be stored at one of these two warehouses so that the transportation and storage space rental costs are minimized.

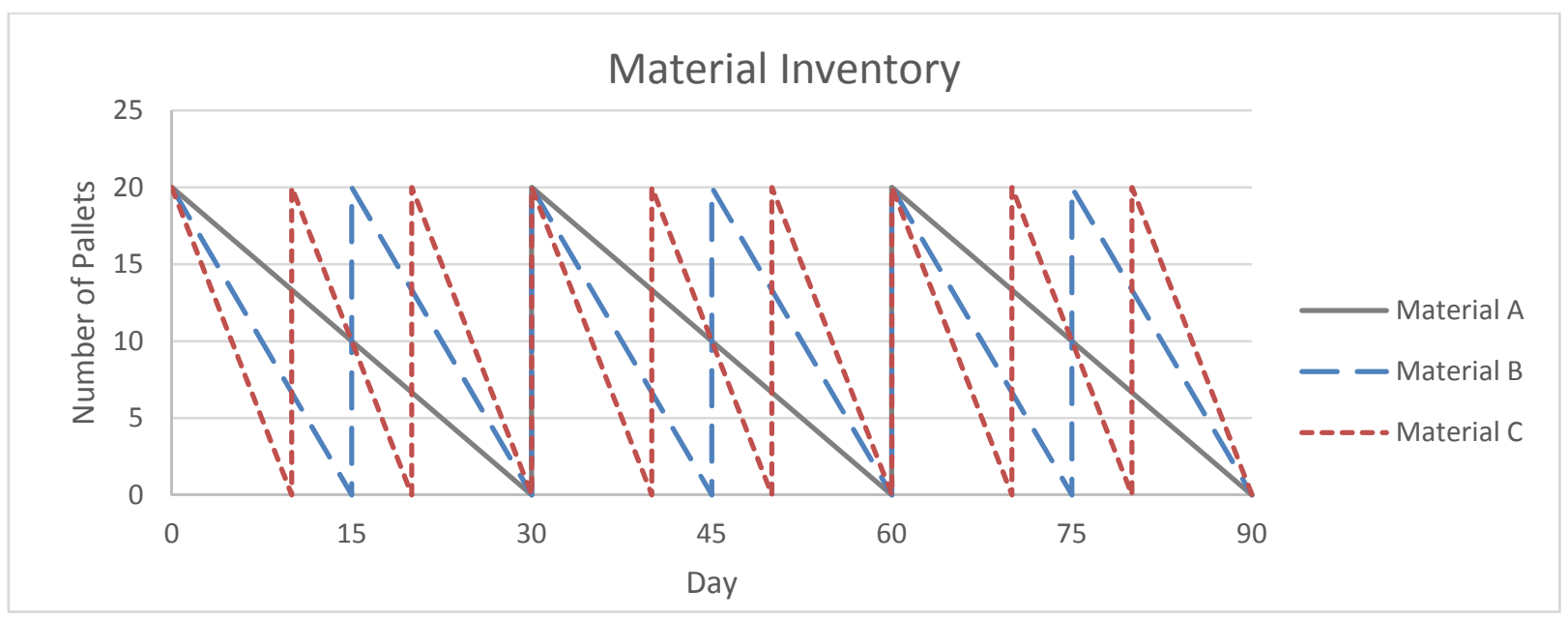

Figure 2 Illustration of the effect of material location allocation decisions on transportation cost. The graphs shows three sample inventories of material $\mathrm{A}, \mathrm{B}$ and $\mathrm{C}$ and their replenishment cycles.

The problem introduced in this paper is not the same as the warehouse forward-reserve area problem, where the forward area inventory (also called the fast-picking area where item units are located in smaller quantities than the reserve area where items are stored in bulk) is replenished by items from the reserve area (Hackman et al., 1990; Berg et al., 1998). In the material location problem the two warehouses are not configured as a two level warehouse where one serves another. The offsite warehouse is not secondary or replenishing storage, rather it is a separate entity from the onsite warehouse and works equally in conjunction with the onsite warehouse to serve the production site. In addition, the cost of using the rented warehouse accrues over multiple time periods while pallets are stored there. While both warehouses (onsite and offsite) may have reserve and forward areas, depending on their configuration and function, the material location problem decides in which locations items/pallets should be stored, but not where and how they are stored in the warehouses. Therefore, rather than improving the item picking operations or configuration of a warehouse, this paper aims at determining which warehouse each item should be stored with respect to their multi-period demands derived from production, delivery, and outbound schedules (i.e., represented by the flows into and out of each location shown in Figure 1).

The research that considers using both owned warehouse and rented warehouse can be found in the inventory control literature, which determines an optimal reorder quantity or time to replenish the stock when the rented warehouse is utilized to store excess inventory. The two warehouse inventory modeling problem was introduced by Hartley (1976) and later was developed to include realistic aspects of the inventory system, such as item deterioration (Bhunia \& Maiti, 1998; Yang, 2004; 2006; Rong et al., 2008; Hsieh et al., 2008; Lee \& Hsu, 2009; Thangam \& Uthayakumar, 2010; Liang \& Zhou, 2011), and backlogging (Goswami \& 
Chaudhuri , 1992; Bhunia \& Maiti, 1998; Zhou, 2003; Yang, 2004; Yang, 2006; Rong et al., 2008; Hsieh et al., 2008; Jaggi \& Verma, 2008). In addition, other issues such as stock-level dependent demand (Zhou \& Yang, 2005; Mondal et al., 2007; Bhunia et al., 2011), item quality (Chung et al., 2009) and trade credit (Thangam \& Uthayakumar, 2010; Liang \& Zhou, 2011) are incorporated to reflect different cases of the inventory system. Different from the classical models that focus on the inventory level of a single item, Maiti et al. (2006) introduced a nonlinear model and applied real-code genetic algorithm to solve a variant of the problem, which involves multi-item inventory levels. Yu (2007) proposed an inventory policy that considers producer's inventory in addition to distributor's inventory, which is separated into two warehouses. Even though the two warehouse inventory problem takes the amount of space rented into account, it does not determine where items should be stored when they are delivered. Like other inventory models, the main focus of the two warehouse inventory modeling problem is to determine how much and when to purchase items rather than allocating items to different warehouses after they are purchased.

Another research area involving two warehouses is the tool switching problem that identifies locations of tools or non-consumable items, in order to reduce or avoid production disruptions due to machine tool switching. Each machine has its own storage with limited capacity, which is called the primary storage or magazine and used to store the tools that can be accessed directly by the machine. The excess tools are kept in a secondary storage location. Moving these excess tools back to the primary storage requires that the longer machine halt, thus leading to low productivity. Therefore, the tool switching problem addresses how to arrange nonconsumable machine tools into the available slots of the tool magazine, so that the machine can keep running without stopping due to missing tools. Even though the problem considers two kinds of storage, its nature is far different from our problem, which addresses storage space rental and transportation cost. In addition, the material-location selection problem deals with multiple consumable materials in which each material consists of multiple items or pallets and can be stored in multiple locations. For more details on of the tool switching problem, refer to surveys by Tang \& Denardo (1988), Matzliach \& Tzur (2000) and Carma et al., (2007). Finally, refer to Rowenhorst et al. (2000) and Gu et al. (2007; 2010) for comprehensive summaries on the current state-of-the-art for warehouse design and management.

To the best of our knowledge, this is the first research that considers the problem of selecting item locations in the presence of owned and rented warehouses. As illustrated by the simple example above (Figure 2), depending on how items are placed into the two warehouses, the resulting transportation and storage space rental costs can be substantially different. The focus of this study is to consider various material-location selection policies to identify locations to store items and study the effect of these policies on transportation and storage space rental costs.

\section{Problem Description}

The two warehouse material-location selection problem considered in this paper consists of one production plant, one owned warehouse and one third-party (3PL) warehouse or rented warehouse, which we refer to as production warehouse and rented warehouse in the remainder of this paper, respectively (see Figure 3). The rented warehouse is located outside the production site, but is assumed to be in close proximity to it. Therefore, the pallets stored offsite can be transferred to onsite locations (either the production plant or production warehouse) upon 
request. Both warehouses supply raw materials to the production plant and serve as intermediate storage locations for finished goods before being shipped to distribution centers or customers. The production warehouse has a limited capacity, in contrast to the rented warehouse which is assumed to have infinite capacity since it is the responsibility of the 3PL to accommodate any storage request from the manufacturer.

The production plant does not have a storage area, so every pallet that goes into the production plant is immediately consumed. Each supplier supplies a material in multiple quantities in a given shipment. Outbound pallets are transshipped to a different warehouse (finished goods and distribution warehouse) for consolidation. In addition, each pallet is assumed to consume the same unit of floor space. However, the proposed models can be easily modified to account for different pallet sizes by having their sizes treated as a parameter.

It is assumed that the shipment schedule of all incoming production materials and the production schedule are known to the warehouse managers so that they can determine where to receive and store pallets. In practice, the schedules or plans can be obtained prior to the production run based on supplier and customer contracts managed by the procurement and marketing departments, respectively. In addition, a time fence or "frozen" period may be applied to guard any changes in the master production plan that may result in a failure of the plan (Silver et al., 1998). In the numerical experiments (see Section 4), it is assumed that the production and shipment schedules for each month plan are only known at the beginning of the month. A time period is defined as a day. The proposed models seek to minimize the transportation cost of moving pallets from offsite to onsite locations and storage space rental cost of storing pallets at offsite locations. Both onsite and offsite warehouses work in conjunction with each other. That is, depending on the material location policy, some materials can appear in one or both warehouses while production can request items directly from both locations.

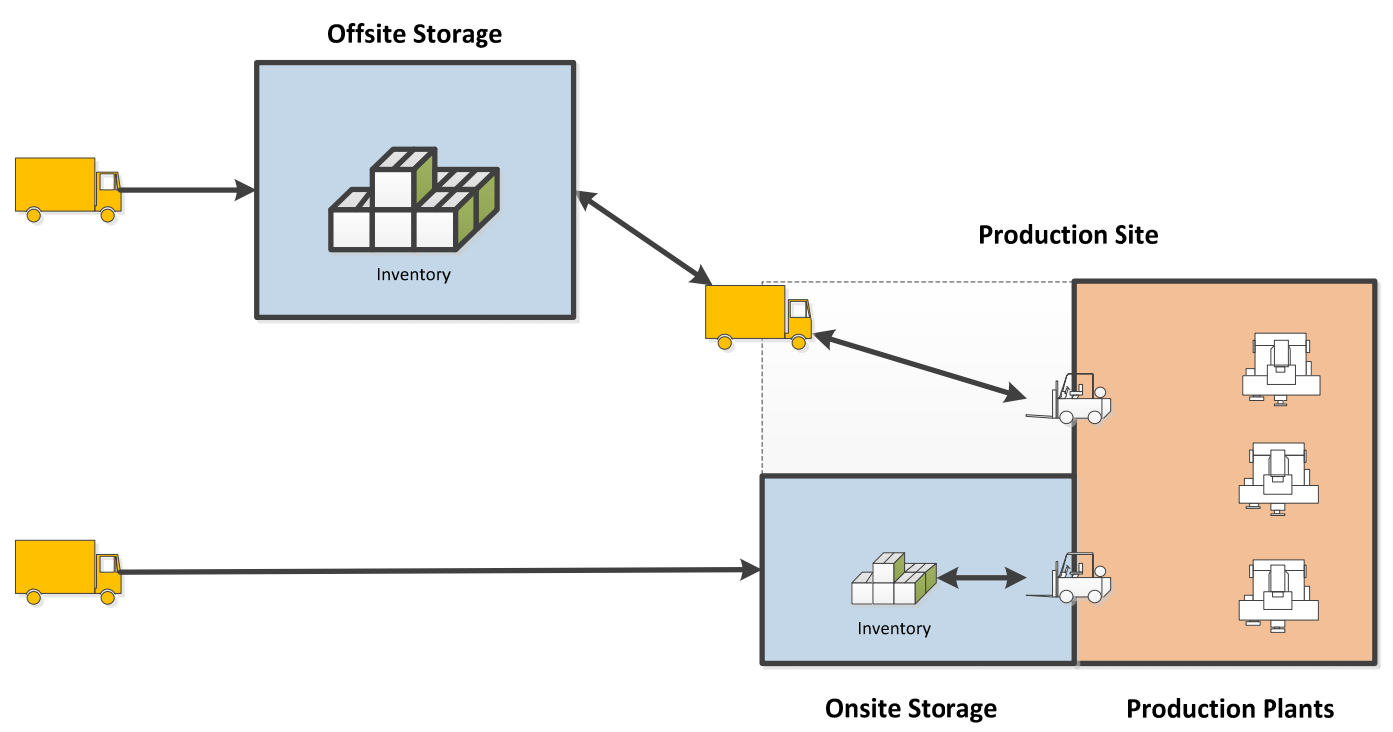

Figure 3 A two warehouse system 


\section{Formulation of the Two-warehouse Material Location Selection Problem}

In order to accommodate different industrial environments, four different materiallocation policies are proposed with different levels of material location selection restriction. The task for the warehouse manager is to determine which of the material location selection models is most appropriate for their manufacturing environment, therefore in general, there is not a single model that is superior to the others. The choice of a specific material location policy is dependent upon the manufacturing environment and management capabilities with respect to demand characteristics, availability of resources (e.g., item monitoring system and item inspection unit), nature of materials, and supplier contract terms, etc. These four policies are termed: shipment level, material level, material level strict storage and material level flexible storage. To generate material location policies, four time-staged network flow-based optimization models are developed. Below we give general description of these models, which are followed by their mathematical formulations. We first give a detailed mathematical formulation for the shipment level model, which is used as the base-model, it is then modified to formulate the other models by introducing additional criteria/restrictions. An important note that must be stressed is that the pallet flows optimized in the models are not the material location policies themselves. These flows are simply used to capture pallet transshipment activities that may happen if the warehouse manager carries out these operations optimally according to the known shipment and production schedules. Even though the pallet flows can be used as an operational guideline or decision support plan, the main objective of the paper is to answer the following critical questions:

1. Where to store each material in each time period?

2. Where to receive each material delivered by suppliers in each time period?

The restrictions incorporated into each policy are summarized as follows:

1. Shipment Level policy decides where to receive each shipment (Figure 4-a).

2. Material Level policy classifies each material as either an onsite material or an offsite material. All pallets whose type belongs to the onsite material category are received onsite; otherwise, they are received offsite (Figure 4-b).

3. In addition to the material classification in the second model, the Material Level Strict Storage policy stores all pallets of a certain material type in that material's classified location (Figure 4-c).

4. Instead of having all pallets of the same material stored in the same location, the Material Level Flexible Storage policy specifies an onsite capacity limit for each onsite material. Also, the onsite storage is replenished by pallets moved from the offsite storage based on a continuous release pattern (Figure 4-d).

The level of restrictions these policies put on receiving and storage locations are summarized in Table 1 and listed based on their management simplicity. While the policies and their mathematical formulations are conceptualized based on a real manufacturing environment, they are general enough to be adapted for various industrial settings. 


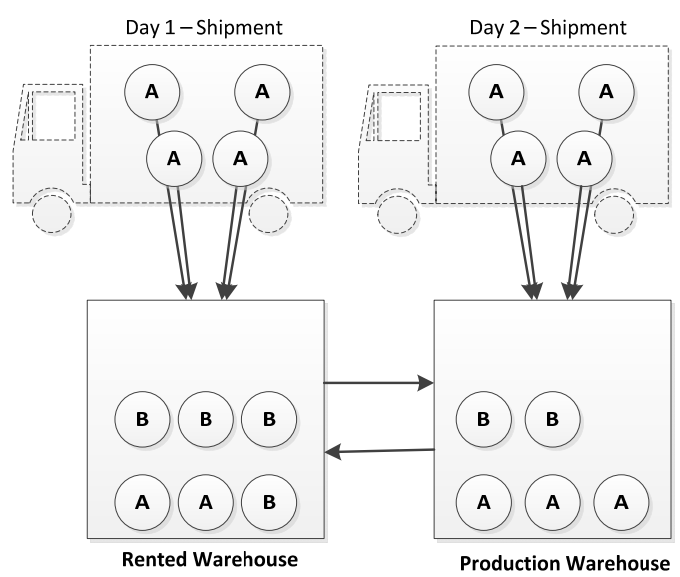

Figure 4-a Shipment Level determines where to receive each shipment and where to store each item

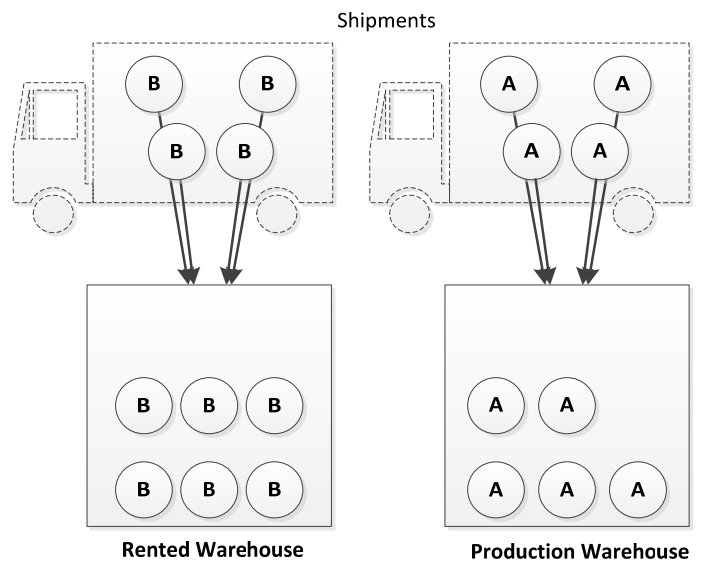

Figure 4-c Material Level Strict Storage determines where to receive and store each material

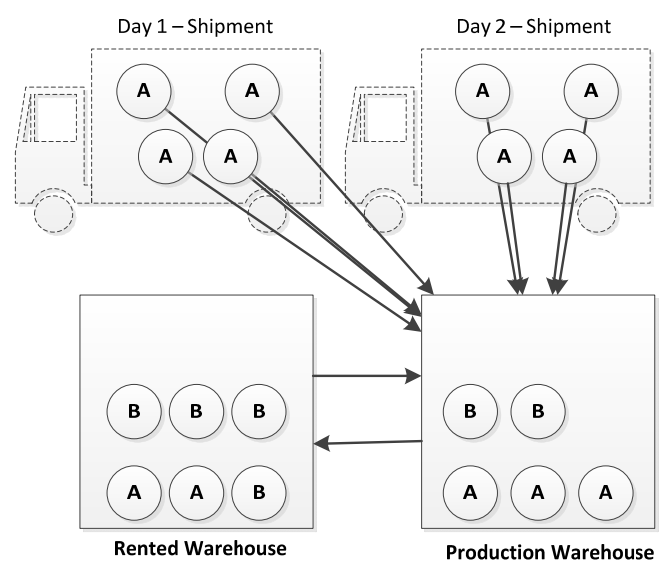

Figure 4-b Material Level determines where to receive each material and where to store each item

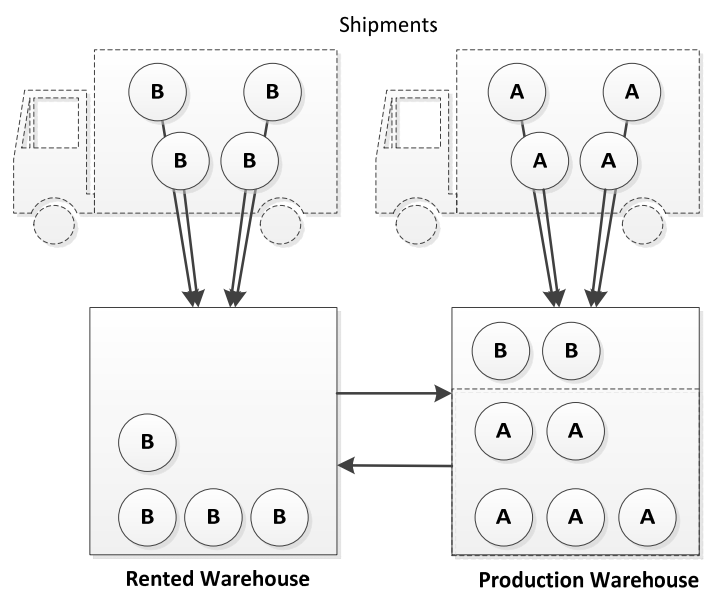

Figure 4-d Material Level Flexible Storage determines where to receive each material and specifies a storage limit in the production warehouse for each onsite material. Also, it continuously replenishes the onsite inventories with the onsite materials stored offsite 
Table 1 Four material-location policies with different levels of restriction (i.e. $Y=Y e s, N=N o, Y^{*}=$ partially

Yes, I = considering each individual item, $\mathrm{S}$ = considering each shipment, $\mathbf{M}$ = considering each material)

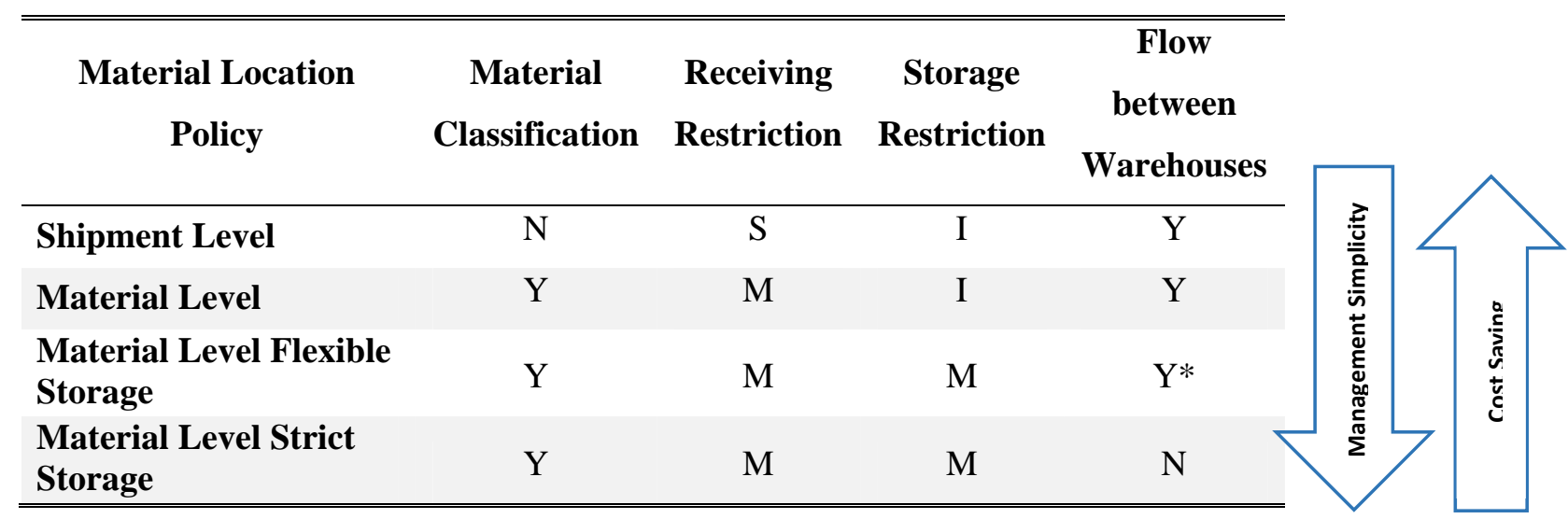

Below we first define the problem notation, which is followed by the formulation of each material location model. The relationship between the problem data and the system considered, and the pallet flows optimized by the models are summarized in Figures 5 and 6, respectively.

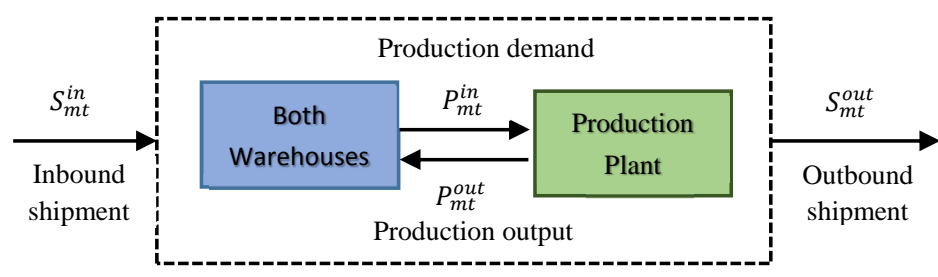

Figure 5 Problem Data

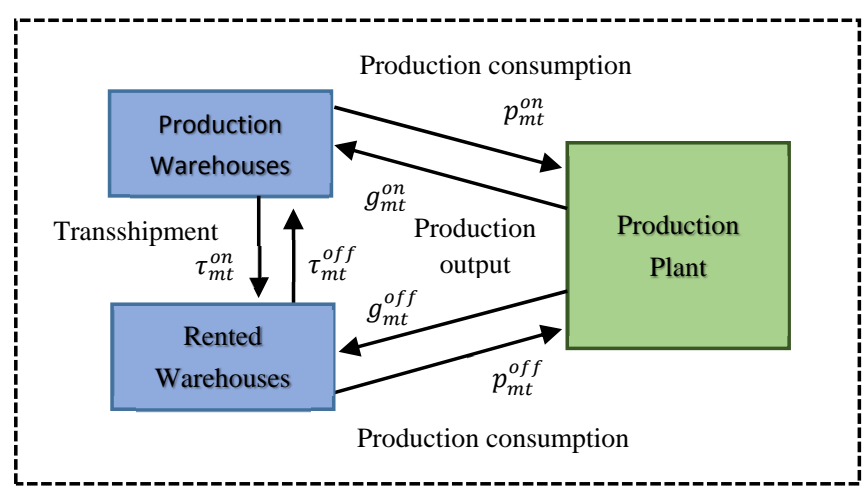

Figure 6 Pallet flows optimized by the models 


\section{Sets:}

$M$ : set of materials indexed with $m$.

$\mathcal{T}$ : set of time periods, indexed with $t$, in the current model execution in which time 1 represents the first period that pallets are allowed to be moved and so on. Note time 0 is reserved for the initial period in which there is no pallet movement activity, so it is not included in the set.

\section{Parameters:}

$P_{m t}^{i n}$ : number of pallets of material $m$ moved to the production plant in period $t$ (i.e., production demand).

$P_{m t}^{\text {out }}$ : number of pallets of material $m$ moved out of production plant in period $t$ (i.e., excess materials or finished goods).

$S_{m t}^{\text {in }}$ : number of pallets of material $m$ received from suppliers in period $t$ (i.e., inbound shipment).

$S_{m t}^{\text {out }}$ : number of pallets of material $m$ moved to the finished goods warehouse for consolidation in period $t$ (i.e., outbound shipment).

$Q_{m}^{\text {off }}$ : number of pallets of material $m$ stored offsite at time $t=0$.

$Q_{m}^{o n}$ : number of pallets of material $m$ stored onsite at time $t=0$.

$K$ : capacity of onsite warehouse (in pallets).

$\mathfrak{M}_{1}, \mathfrak{M}_{2}$ : large constant numbers.

$C^{r}$ : rented storage cost per pallet.

$C^{t}$ : transportation cost per pallet.

\section{Variables:}

$\tau_{m t}^{o n}$ : number of material $m$ pallets moved from production warehouse to rented warehouse in period $t$.

$\tau_{m t}^{o f f}$ : number of material $m$ pallets moved from rented warehouse to production warehouse in period $t$.

$p_{m t}^{o n}$ : number of material $m$ pallets moved from production warehouse to production plant in period $t$.

$p_{m t}^{o f f}$ : number of material $m$ pallets moved from rented warehouse to production plant in period $t$.

$q_{m t}^{o n}$ : number of material $m$ pallets stored onsite at the end of period $t$.

$q_{m t}^{o f f}$ : number of material $m$ pallets stored offsite at the end of period $t$.

$g_{m t}^{o n}$ : number of material $m$ pallets moved from production plant to production warehouse in period $t$. 
$g_{m t}^{o f f}$ : number of material $m$ pallets moved from production plant to rented warehouse in period $t$.

$w_{m t}^{o n}$ : number of material $m$ pallets shipped outbound from production warehouse in period $t$.

$w_{m t}^{o f f}$ : number of material $m$ pallets shipped outbound from rented warehouse in period $t$.

1. Shipment Level policy. The shipment level policy determines where to receive each individual shipment, in order to avoid shipment splitting. The model captures a system where the warehouse manager decides periodically where to receive each inbound shipment according to available information (i.e. item delivery, shipping and production schedules). In other words, it is employed for the case in which the product demand has relatively high fluctuation or the demand pattern is not well established or known, causing supplies to be ordered only as needed. In such cases, the warehouse manager periodically decides where to receive each shipment according to the most recent information on the production plan, demand shipment due-date, and storage availability (i.e., not based on historical data), in order to avoid additional transportation cost accrued due to changes in material-location policies. A disadvantage of using this policy is that the warehouse manager has to frequently determine where to receive and store pallets. In addition, if some materials need to be inspected upon arrival, an inspection unit (e.g. machine and labor) has to be installed in both warehouses. To formulate the policy, an additional set of variables is introduced. Later, the model is used as a base-model for creating the other policies in order to capture different warehouse management environments, and also serves as a benchmark for the other models.

$$
y_{m t}=1 \text { if the shipment of material } \mathrm{m} \text { received at time } \mathrm{t} \text { is delivered onsite; otherwise, } 0 .
$$

The model is formulated as:

$$
\min \sum_{m \in M} \sum_{t \in \mathcal{T}}\left(\tau_{m t}^{o f f}+\tau_{m t}^{o n}+p_{m t}^{o f f}+g_{m t}^{o f f}\right) * C^{T}+\sum_{m \in M} \sum_{t \in \mathcal{T}} q_{m t}^{o f f} * C^{r} \text { (Total Cost) }
$$

Subject to:

$$
\begin{array}{ll}
q_{m t}^{o n}=q_{m(t-1)}^{o n}+\mathrm{y}_{m t} S_{m t}^{i n}-\tau_{m t}^{o n}+\tau_{m t}^{o f f}+g_{m t}^{o n}-p_{m t}^{o n}-w_{m t}^{o n} & \forall m \in \boldsymbol{M}, t \in \boldsymbol{T} \\
q_{m t}^{o f f}=q_{m(t-1)}^{o f f}+\left(1-\mathrm{y}_{m t}\right) S_{m t}^{i n}+\tau_{m t}^{o n}-\tau_{m t}^{o f f}+g_{m t}^{o f f}-p_{m t}^{o f f}-w_{m t}^{o f f} & \forall m \in \boldsymbol{M}, t \in \boldsymbol{T} \\
\sum_{m \in M} q_{m t}^{o n} \leq K & \forall t \in \mathcal{T} \\
P_{m t}^{i n}=p_{m t}^{o f f}+p_{m t}^{o n} & \forall m \in \boldsymbol{M}, t \in \mathcal{T} \\
P_{m t}^{o u t}=g_{m t}^{o f f}+g_{m t}^{o n} & \forall m \in \boldsymbol{M}, t \in \mathcal{T} \\
S_{m t}^{o u t}=w_{m t}^{o f f}+w_{m t}^{o n} & \forall m \in \boldsymbol{M}, t \in \mathcal{T} \\
Q_{m}^{o f f}=q_{m 0}^{o f f} & \forall m \in \boldsymbol{M} \\
Q_{m}^{o n}=q_{m 0}^{o n} & \forall m \in \boldsymbol{M} \\
q_{m t}^{o f f}, q_{m t}^{o n}, p_{m t}^{o f f}, p_{m t}^{o n}, \tau_{m t}^{o f f}, \tau_{m t}^{o n}, w_{m t}^{o f f}, w_{m t}^{o n}, g_{m t}^{o f f}, g_{m t}^{o n} \geq 0 & \forall m \in \boldsymbol{M}, t \in \boldsymbol{T} \\
y_{m t} \in\{0,1\} & \forall m \in \boldsymbol{M}, t \in \boldsymbol{T}
\end{array}
$$


The objective function minimizes the total storage rental and transportation cost for bringing pallets onsite or offsite. The model is subjected to the flow balance constraints (2) and (3). The onsite storage space usage is limited by the production warehouse's capacity (4). Note constraint (4) assumes that each pallet consumes the same amount of space (e.g., standard-size pallet). However, this constraint can be easily relaxed to account for different space required by each material pallet by simply using a per-pallet space multiplier. In addition, the pallet transshipment activities are performed based on schedule constraints (5)-(7) for production demand, production output, and outbound shipments, respectively. Constraints (8) and (9) initialize the onsite and offsite inventories while constraints (10) and (11) are non-negativity constraint and binary constraint, respectively.

2. Material Level policy. Instead of considering each shipment individually, the material level policy categorizes each material as either an onsite or offsite material. Each material is assigned to one delivery location to simplify receiving operations. Although pallets are expected to be kept in the warehouse where they are delivered due to transportation cost, they are allowed to flow between the warehouses as determined by the warehouse manager. In other words, the policy assists the warehouse manager in classifying materials but does not restrict their decision on where to store pallets and which pallets shall be moved. These decisions are made based upon the judgment of the warehouse manager with respect to the system environment and information available, such as item expiration date and changes in demand/production plan after the policy is created. Since the storage location is not a major concern of the model, this strategy may be applied to a system that consists of a relatively low number of materials whose items have relatively similar and high consumption rates, or a system with perishable or short-life items such as fresh food. In this kind of environment, items are not expected to remain in storage for a long time before being consumed by the production plant. To classify materials, additional variables $x_{m}$ are introduced and base model balance flow constraints (2) and (3) are replaced by constraints (12) and (13), and constraint (11) is removed:

$$
x_{m}=1 \text { if material } m \text { is an onsite material; otherwise, } 0 .
$$

$$
\begin{array}{ll}
q_{m t}^{o n}=q_{m(t-1)}^{o n}+\mathrm{x}_{m} S_{m t}^{i n}-\tau_{m t}^{o n}+\tau_{m t}^{o f f}+g_{m t}^{o n}-p_{m t}^{o n}-w_{m t}^{o n} & \forall m \in \boldsymbol{M}, t \in \mathcal{T} \\
q_{m t}^{o f f}=q_{m(t-1)}^{o f f}+\left(1-\mathrm{x}_{m}\right) S_{m t}^{i n}+\tau_{m t}^{o n}-\tau_{m t}^{o f f}+g_{m t}^{o f f}-p_{m t}^{o f f}-w_{m t}^{o f f} & \forall m \in \boldsymbol{M}, t \in \mathcal{T} \\
x_{m} \in\{0,1\} & \forall m \in \boldsymbol{M}, t \in \mathcal{T}
\end{array}
$$

3. Material Level Strict Storage policy. In addition to linking the receipt of each material to one receiving location, the material level strict storage policy stores pallets of each material only in their respective material location (i.e. onsite material vs. offsite material) for item tracking and rotating purposes. In other words, it provides an explicit rule/policy to store pallets so that workers can easily identify their storage locations. Thus, the material level policy and material level strict storage policy have one significant difference: the latter policy does not allow pallets to flow between warehouses, except the production plant, while the former policy allows pallets to be moved back-and-forth between the two warehouses. The drawback of the material level strict storage policy is that the production warehouse might have relatively lower onsite-space utilization due to the strict restrictions on material storage location. In addition, if the warehouse size is relatively small, compared to the quantity of each material, some of the fast 
moving materials with high volumes may be classified as offsite due to the production warehouse's limited storage capacity and therefore are stored entirely offsite. This may lead to multiple pallet transshipments between the rented and production warehouses.

Since each material is classified as either onsite or offsite material, $x_{m}$ variables are defined the same as in the material level model. As the inventory level of each onsite material may fluctuate over time due to the production consumption and outbound demands, we introduce a set of variables $r_{m}$ that reserve a certain amount of onsite storage space for each onsite material (see below). While the flow operations are simplified as pallets of each material are stored in their respective location, constraints (15) - (17) maintain the homogeneity of each material at its respective location. Constraint (18) ensures that the amount of area reserved for onsite materials is less than the warehouse capacity. In addition to these constraints, constraints (4) - (10) and $(12)$ - (14) remain the same as the material level model. Note: although the transportation cost and constraints (15) - (17) ensure that no pallets of a material will originate from the location where the material does not belong, for ease of generating solutions the demand constraints (5) (6), except for $\mathrm{t}=1$, can be broken down into two constraints; one for each warehouse with $x_{m}$ as a pallet flow decision variable (e.g. $p_{m t}^{o n}=\mathrm{x}_{m} P_{m t}^{i n}$ and $p_{m t}^{o f f}=\left(1-\mathrm{x}_{m}\right) P_{m t}^{i n}$ for constraint (5)).

$r_{m}=$ amount of onsite storage space reserved for material $m$ pallets

$$
\begin{array}{ll}
r_{m} \leq \mathrm{x}_{m} K & \forall m \in \boldsymbol{M} \\
q_{m t}^{\text {on }} \leq r_{m} & \forall m \in \boldsymbol{M}, t \in \mathcal{T} \\
q_{m t}^{\text {off }} \leq\left(1-\mathrm{x}_{m}\right) \mathfrak{M}_{1} & \forall m \in \boldsymbol{M}, t \in \mathcal{T} \\
\sum_{m \in \boldsymbol{M}} r_{m} \leq K & \\
r_{m} \geq 0 & \forall m \in \boldsymbol{M}
\end{array}
$$

4. Material Level Flexible Storage policy. In order to maintain item storage homogeneity and ease of maintaining inventory locations while better utilizing onsite space, the material level flexible storage policy specifies a storage space limit $l_{i}$ for each onsite material, and requires materials to be stored onsite with respect to their limits. Although the method prioritizes onsite materials over the offsite materials for onsite storage, it also allows some of the offsite materials to be moved into the production warehouse if there is available space. By continuously replenishing the production warehouse storage with the onsite pallets that are temporarily stored offsite, the method guarantees that the onsite materials, if any, are always available onsite for quick access. Also, it provides both an explicit material receiving policy and a material storage policy, so that workers can determine directly where to look for each material. This policy is similar to the common practice considered in the two warehouse inventory modeling problem (Bhunia \& Maiti, 1998; Zhou, 2003; Yang, 2004; Bhunia et al., 2011; Liang \& Zhou, 2011) in which the items stored in the rented warehouse are consumed first or continuously transferred to the owned warehouse. However, the material level flexible storage policy may not achieve the same level of stock rotation as the material level, since it allows for keeping onsite materials in separate locations. Nevertheless, the rotation process would be improved compared to the material level policy. This would be a result of the already received onsite pallets only flowing from the rented warehouse to the production warehouse; therefore, enhancing item sortation. 
Similar to the material level policy, the variables $x_{m}$, the constraints (4) - (10) and the constraints (12) - (14) remain the same. Constraints (20) and (21) below bound the onsite storage space limit of each onsite material to be less than the onsite capacity. Constraints (22) - (24) transfer pallets of onsite materials to the production warehouse in order to comply with their limits. In addition, the constraints allow pallets of offsite materials to be moved into the onsite warehouse by assigning zero to $l_{m}$ for the offsite materials, causing a large $\mathfrak{M}_{1}$ positive bound on their onsite inventory, while the onsite materials are given priority to utilize onsite storage space due to their non-zero $l_{m}$ and constraint (23).

$l_{m}=$ amount of onsite storage space reserved for material $m$ pallets.

$v_{m t}=1$ if there are pallets of onsite material $m$ stored offsite in period $t$.

$$
\begin{array}{ll}
l_{m} \leq \mathrm{x}_{m} K & \forall m \in \boldsymbol{M} \\
\sum_{m \in M} l_{m} \leq K & \\
q_{m t}^{o n}-l_{m} \leq\left(1-x_{m}\right) \mathfrak{M}_{1} & \forall m \in \boldsymbol{M}, t \in \mathcal{T} \\
l_{m}-q_{m t}^{o n} \leq\left(1-v_{m t}\right) \mathfrak{M}_{1} & \forall m \in \boldsymbol{M}, t \in \mathcal{T} \\
q_{m t}^{o f f} \leq \mathrm{v}_{m t} \mathfrak{M}_{1} & \forall m \in \boldsymbol{M}, t \in \mathcal{T} \\
\mathrm{v}_{m t} \in\{0,1\} & \forall m \in \boldsymbol{M}, t \in \mathcal{T} \\
l_{m} \leq 0 & \forall m \in \boldsymbol{M}
\end{array}
$$

\section{Computational Experimentation}

\subsection{Data and Case Study}

The data used in this paper is based on research collaboration between Center for Excellence Logistics and Distribution at University of Missouri and a Fortune 100 manufacturer of agricultural chemicals who supplies both US and global markets. The data used in this analysis is representative of 12-months' worth of pallet movement transactions for over 1,400 materials, which belong to one of four main categories, namely finished goods, packaging materials, raw materials and semi-finished goods. During the 12-month period, approximately 130,000 pallet movements were recorded. The pallet receiving, production, and shipping schedules were scaled to protect data confidentiality. The initial inventory levels at the beginning of the 12-month period are constructed by tracing back the pallet movement transactions (Wutthisirisart et al., 2012).

The manufacturer utilizes a 3PL warehousing company that is responsible for raw material and finished goods storage. The 3PL company rents a warehouse located outside the production site on behalf of the manufacturer, and charges the manufacturer for every pallet stored in the warehouse and for every pallet transferred between the warehouse and the production site. In addition to renting the offsite storage through the 3PL, the manufacturer also owns warehouses, referred to as production warehouses that are located at the production site. The onsite warehouses are operated by the manufacturer. Pallet transportation between the 
production warehouse and production plant are performed by forklifts. However, transportation in-and-out of the production site is performed by the 3PL.

The production plant consumes multiple raw materials, including packaging materials, and produces multiple finished goods. The materials can be supplied by either production or rented warehouses. The finished goods are temporarily stored in the same production warehouse as raw materials before being transported to a separate offsite rented warehouse (i.e., distribution center) for shipment consolidation.

In addition to the warehouse management team, who are responsible for pallet storage and supplying materials to the production plants, the manufacturer also has a material procurement team, who are responsible for purchasing raw materials from suppliers. The manufacturer determines a pallet receiving location for each material shipment delivered from their suppliers, and no explicit material-location rule exists. The purchased quantities of materials and purchasing timing are not solely based on the production demand, but also on the prices that are currently offered by suppliers. Therefore, materials can be purchased in quantities that exceed the production warehouse capacity. In fact, the production warehouse capacity is only a secondary consideration when making procurement decisions.

Initially, the manufacturer decided to close down some onsite warehouses and move some of the items stored there to the rented warehouse. However, analysis of the pallet movement transactions and utilization of the production warehouses indicates that there is a relatively high number of pallets moving back and forth between the onsite locations and offsite rented warehouse and that the production warehouse capacity is not always fully utilized. Therefore, in order to improve item accessibility and reduce transportation cost, a heuristic approach was implemented by the manufacturer to bring in more fast moving pallets (i.e., with a high consumption rate) from the rented warehouse to the production warehouse, and also decide where to receive and store select products onsite, based on a heuristic-based fast-movement index (Wutthisirisart et al., 2012). In this paper, we propose optimization models considering various material handling environments to develop more rigorous material location policies and compare their performance. We describe the experimental design in Section 4.2 and analyze results of numerical experiments in Section 4.3.

\subsection{Experimental Design}

In the numerical experiments, storage space rental cost is assumed to be $\$ 0.2$ per pallet per day and transportation cost is assumed to be $\$ 4.9$ per pallet transferred between onsite and offsite locations. Annual data for 12 months is split into four datasets according to the calendar quarters (i.e., 3 months each). For the material level, material level strict storage, and material level flexible storage models, each set is used to create a material-location policy that is used for the next three months.

The experiments are performed in two phases. In phase one, material location policies are created by running the material level, material level strict storage and material level flexible storage models described in Section 3 with the quarterly datasets. The solutions of the three models results in three material-location policies. In phase two, the material-location policies determined in phase one are employed with two updating schemes and the total costs are calculated in order to observe the performance of the models with respect to the manufacturer's procurement and production plans. The two updating schemes are: 1) a quarterly updating in 
which policies are updated every three months, and, 2) a one-time updating in which policies are created once (using the first quarter dataset) and used for the rest of the planning period. Since the shipment level policy is only applicable for the situation in which the warehouse manager decides to handle each shipment individually according to their expertise and available information, it is solved at the beginning of each month to determine a delivery location of each inbound shipment. Even though pallets are expected to be stored where they are received and the results of the model can be used as an operational plan, in practice, the decision on where to store and move the pallets within the warehouse is left to the warehouse manager's judgment.

In order to evaluate the performance of each material location policy in terms of cost, it is assumed that the material flow decisions are carried out optimally with respect to the materiallocation policy under consideration. The optimal flows are calculated by solving slightly modified versions of the original optimization models described in Section 3. These modifications include

1) For the material level, material level strict storage, and material level flexible storage models, the decision variables $x_{m}$ become simply parameters, whose values are set according to the corresponding material location policies.

2) For the material level strict storage model, the onsite material is allowed to be stored offsite only when the onsite warehouse is full, in order to maintain the material's homogeneity. To enforce this requirement when implementing the material location policy for this model, a new term $\sum_{\forall t \in \mathcal{T}} d_{t} \mathfrak{M}_{2}$ is added to the objective function (1) to penalize offsite storage usage of the onsite materials, where $d_{t}$ is a new variable representing unutilized space in the production warehouse in period $t$ and $\mathfrak{M}_{2}$ is a large constant. The following set of constraints defines variable $d_{t}$ and helps prioritize the onsite space.

$$
K-\sum_{m \in M} q_{m t}^{o n} \cdot x_{m} \leq d_{t} \quad \forall t \in \mathcal{T}
$$

In addition, $r_{m}$ and its related constraints are dropped to prevent onsite pallets from moving to the rented warehouse when the production warehouse capacity is not reached.

3) For the material level flexible storage model, the variables $l_{m}$ related to the onsite material storage capacity also become parameters, values of which are set based on the solution of the original model.

In addition to updating material location policies resulting from the material level, material level strict storage and material level flexible storage models every quarter (i.e., 3 months) and implementing them in the following quarter, we also consider the situation where policies are generated only using the first quarter data. As mentioned above, this is referred to as the one-time policy-updating scheme. The two policy updating schemes are compared with each other in order to assess the effect of material re-allocation caused by updating the material location policies every quarter on the transportation cost as well as the effect of demand fluctuations. The material location policies are implemented for each of the nine months from April until December (recall that the first three months are used to generate the initial material location policies). 


\subsection{Result and Discussion}

The models were coded in C++ with Qt library and solved using the GUROBI 4.5 commercial solver (http://www.gurobi.com/). All model instances are terminated after their solutions reach $0.01 \%$ optimality gap, except for the material level flexible storage model that is terminated when the gap moves below 1.5\%. In the first phase, the material-location policies were generated with quarterly datasets. The number of onsite materials selected by each model are shown in Table 2 (out of a possible 1400 materials). The results show that $10 \%$ to $40 \%$ of all materials are selected as onsite materials. Based on the quarterly changes in the material locations, this suggests that there are some changes in the demand (i.e. production plan and outbound shipment plan). This can result in high transportation costs when materials are reallocated due to the material location policy update.

Table 2 Phase 1 Results - number of materials classified as onsite material for different material location models.

\begin{tabular}{llll}
\hline Material Location Policies & $\mathbf{1}^{\text {st }}$ Quarter & $\mathbf{2}^{\text {nd }}$ Quarter & $\mathbf{3}^{\text {rd }}$ Quarter \\
\hline Material Level & 671 & 374 & 261 \\
Material Level Strict Storage & 351 & 471 & 291 \\
Material Level Flexible Storage & 358 & 200 & 149 \\
\hline \hline
\end{tabular}

In the second phase, each material location policy is implemented assuming that pallet flows are optimized (see above for details) based on the scheduling plans available at the beginning of each month for each of the next three months that follow the quarterly dataset used to create the policy. The total costs resulting from the implementation of these material location policies for each month are shown in Table 3 and 4. Table 3 includes cost figures for the actual operations that occurred during the 12-month period under consideration and for the shipment level model, which optimally decides where to receive and store each pallet. 
Table 3 Comparison of the performance of the Shipment Level

Policy to current operations for the case study

\begin{tabular}{c|rr|rr}
\hline \hline Month & \multicolumn{2}{|c|}{ Current Operation } & \multicolumn{2}{|c}{ Shipment Level } \\
& \multicolumn{2}{|c|}{} & \multicolumn{2}{|c}{ Model } \\
\hline & Trans. & Rent & Trans. & Rent \\
$\mathbf{4}$ & 26,817 & 76,593 & 17,152 & 52,365 \\
$\mathbf{5}$ & 26,791 & 78,697 & 3,874 & 53,344 \\
$\mathbf{6}$ & 26,324 & 79,057 & 4,139 & 57,220 \\
$\mathbf{7}$ & 31,684 & 83,567 & 3,369 & 63,691 \\
$\mathbf{8}$ & 38,130 & 86,033 & 4,126 & 65,515 \\
$\mathbf{9}$ & 25,884 & 79,065 & 3,600 & 57,370 \\
$\mathbf{1 0}$ & 23,897 & 77,905 & 3,737 & 56,106 \\
$\mathbf{1 1}$ & 25,443 & 73,163 & 2,675 & 51,693 \\
$\mathbf{1 2}$ & 23,897 & 75,424 & 1,746 & 54,925 \\
\hline Sub-Total & 248,867 & 709,503 & 44,418 & 512,229 \\
Total & \multicolumn{2}{|c|}{$\$ 958,370$} & \multicolumn{2}{|c}{$\$ 556,647$} \\
\hline \hline
\end{tabular}

Table 4 Comparison of the performance of warehouse material location selection models using a quarterly policy updating scheme. The total cost is separated into transportation and storage rental costs.

\begin{tabular}{|c|c|c|c|c|c|c|}
\hline \multicolumn{7}{|c|}{ Quarterly Policy Updating Scheme } \\
\hline \multirow[t]{2}{*}{ Month } & \multicolumn{2}{|c|}{ Material Level Model } & \multicolumn{2}{|c|}{$\begin{array}{l}\text { Material Level } \\
\text { Strict Storage Model }\end{array}$} & \multicolumn{2}{|c|}{$\begin{array}{l}\text { Material Level } \\
\text { Flexible Storage Model }\end{array}$} \\
\hline & Trans. & Rent & Trans. & Rent & Trans. & Rent \\
\hline 4 & 20,174 & 51,826 & 32,189 & 60,275 & 25,212 & 52,714 \\
\hline 5 & 6,690 & 53,443 & 9,477 & 61,340 & 15,247 & 55,826 \\
\hline 6 & 10,068 & 57,272 & 10,389 & 61,097 & 17,374 & 59,144 \\
\hline 7 & 7,165 & 63,817 & 38,019 & 71,806 & 32,052 & 64,162 \\
\hline 8 & 7,123 & 66,360 & 10,645 & 71,492 & 15,153 & 66,992 \\
\hline 9 & 7,097 & 58,456 & 9,241 & 67,157 & 10,217 & 59,763 \\
\hline 10 & 4,777 & 57,157 & 37,449 & 63,524 & 17,241 & 56,739 \\
\hline 11 & 8,569 & 52,084 & 10,902 & 61,284 & 10,046 & 53,826 \\
\hline 12 & 7,341 & 55,017 & 7,482 & 62,586 & 9,147 & 57,666 \\
\hline Sub Total & 79,003 & 515,431 & 165,793 & 580,562 & 151,689 & 526,831 \\
\hline Total & \multicolumn{2}{|c|}{$\$ 594,434$} & \multicolumn{2}{|c|}{$\$ 746,355$} & \multicolumn{2}{|c|}{$\$ 678,520$} \\
\hline
\end{tabular}

As can be seen in Tables 3 and 4, the material level strict storage model yielded the highest total cost, as would be expected based on its lower onsite space utilization (79\%) compared to the material level model (99\%) and material level flexible storage model (95\%). For the shipment level model and material level model, their costs are on average $7 \%$ different. This implies that if the procurement and production schedules are available to the warehouse manager 
at the beginning of the planning period, the warehouse manager can still obtain relatively low transportation and offsite storage rental costs after classifying each material to be either onsite or offsite material by optimizing their flows according to the schedules, compared to the case in which each shipment is considered and assigned to a location individually - i.e. shipment level policy. However, this requires the warehouse manager to have sufficient experience and staff support in making decisions on where to store and move pallets for each incoming shipment.

Among all three material location models, the material level model yielded the lowest cost - approximately $20 \%$ and $12 \%$ lower cost compared to the material level strict storage and the material level flexible storage policies, respectively. Although these results are only possible when assuming that the warehouse manager carries out the material flow operations optimally, they assist warehouse managers in assessing the performance of their warehouse operations. The results highlight the best possible outcome that can be achieved if a particular material location policy is employed. All four models resulted in lower costs compared to the costs from the current operation in the case study. The decrease in total cost with respect to the cost of the current operations range from $\$ 200,000$ to $\$ 400,000$ among the four material location selection models during the April to December time period. This illustrates the improvement possibility in the current operations that the warehouse manager can gain by applying the material location policies.

Based on the results of the material level strict storage model and the application of the quarterly updating scheme to make the policies reflect the demand trends it highlights that demand fluctuation or seasonality is prevalent in the data. As can be seen in Table 4, after the material location policy is created from quarterly datasets and implemented in the following quarters (i.e., April to June, July to September, and October to December, for the material level strict storage model, the transportation costs for April, July, and October are almost twice as large as the summation of the transportation costs in the remainder of each quarter. The pallet transshipment between offsite and onsite accounts for approximately $50 \%$ of the transportation costs in April, July and October when the policy is updated.

To examine the effect of policy updating on the transportation costs between two warehouses, we re-run the models using a one-time updating scheme. The one-time updating scheme generates material location policies from the first quarter dataset and then implements the policies during the remaining months. The results are shown in Table 5.

Table 5 reveals that there are cost saving to be gained from a conservative policy updating scheme. For both the material level strict storage and material level flexible storage models, more than $70 \%$ of the savings come from the reduction in the transportation cost, while the costs of the material level model between the two policy updating schemes are only $0.7 \%$ different. This is in contrast to the total transportation cost of the material level strict storage and material level flexible storage combined for July and October where the total transportation cost after the quarterly policy updating scheme is applied (i.e., August, September, November and December) is lower than the one-time policy updating scheme $(\$ 82,834$ for the quarterly updating and $\$ 97,816$ for the one-time policy updating). However, the reduction is not large enough to compensate for the reallocation cost in July and October. Compared to the combined total transportation costs in July and October (i.e. \$75,468 for material level strict storage model and $\$ 49,293$ for material level flexible storage models),75\% and $66 \%$ of these costs are paid to 3PL to reallocate materials for the material level strict storage and material level flexible storage, 
respectively. Therefore, in this case, updating the material location policy frequently and implementing it for a relatively short time period may yield a high transportation that cannot be paid off during that time period.

Table 5 Comparison of the performance of warehouse material location selection models using a onetime policy updating scheme. The total cost is separated into transportation and storage rental costs.

\begin{tabular}{|c|c|c|c|c|c|c|}
\hline \multicolumn{7}{|c|}{ Onetime Policy Updating Scheme } \\
\hline \multirow[t]{2}{*}{ Month } & \multicolumn{2}{|c|}{ Material Level } & \multicolumn{2}{|c|}{$\begin{array}{l}\text { Material Level } \\
\text { Strict Storage }\end{array}$} & \multicolumn{2}{|c|}{$\begin{array}{l}\text { Material Level } \\
\text { Flexible Storage }\end{array}$} \\
\hline & Trans. & Rent & Trans & Rent & Trans. & Rent \\
\hline 4 & 20,174 & 51,826 & 32,189 & 60,275 & 25,212 & 52,714 \\
\hline 5 & 6,690 & 53,443 & 9,477 & 61,340 & 15,247 & 55,826 \\
\hline 6 & 10,068 & 57,272 & 10,389 & 61,097 & 17,374 & 59,144 \\
\hline 7 & 8,334 & 63,731 & 11,861 & 66,755 & 14,703 & 64,781 \\
\hline 8 & 7,884 & 65,807 & 13,381 & 67,592 & 18,008 & 66,978 \\
\hline 9 & 4,400 & 57,513 & 12,058 & 61,945 & 11,168 & 59,750 \\
\hline 10 & 4,289 & 56,228 & 9,537 & 60,779 & 10,992 & 58,854 \\
\hline 11 & 6,164 & 51,692 & 10,410 & 59,686 & 11,544 & 53,284 \\
\hline 12 & 9,644 & 54,918 & 8,368 & 61,453 & 12,880 & 55,879 \\
\hline Sub Total & 77,646 & 512,430 & 117,668 & 560,923 & 137,127 & 527,211 \\
\hline Total & \multicolumn{2}{|c|}{$\$ 590,076$} & \multicolumn{2}{|c|}{$\$ 678,591$} & \multicolumn{2}{|c|}{$\$ 664,338$} \\
\hline
\end{tabular}

The reason behind the high reallocation cost stems from the changes or fluctuation in production activities and demands, which are agricultural related. An example of the demand fluctuation in our data can be seen in Figure 7 where the demands of four items selected from the 20 most requested items are plotted. As the demand for each product fluctuates, the material location plan may change from quarter to quarter. For example, since material D is never requested until April, this material might not be classified by the model as an onsite material until a new policy is calculated at the end of June. So, its items would be received offsite until then. Similarly, the demand for material A was at the bottom of the chart during April until June, but its demand was relatively high during the first three months. As such, material A might be selected to be received onsite by the model that generates the policies with the first quarter dataset. However, even though material A is classified as an onsite material, it would not be used until October. In this case, future transportation and storage cost savings might not be high enough to compensate for the reallocation costs. 


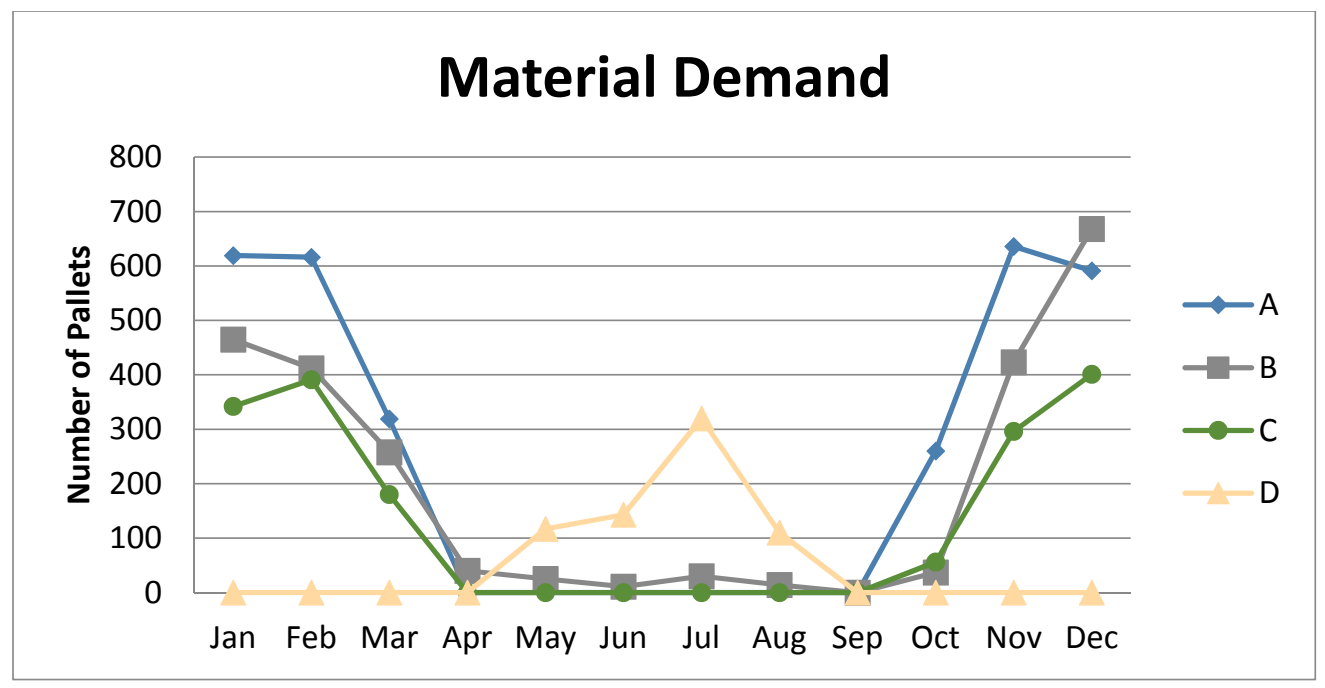

Figure 7 An example of demand fluctuation and seasonality effect for materials A, B, C and D

Due to the seasonality in the data, a conservative updating scheme is preferred to guard against the reallocation cost incurred when the policies are updated. In this case, the shipment level model may be used to decide where to receive each shipment while pallets can be moved to different locations. Although the pallets can be moved, they are expected to be stored where they are delivered. This reflects the relatively low total transportation cost of the shipment level policy, \$44,417, i.e. $100 \%$ of which is incurred through pallet transshipment between the two warehouses. In contrast, instead of executing the shipment level model monthly to determine a delivery location for each shipment, the warehouse manager may opt for a solution in which each material is explicitly classified as either an onsite or offsite warehouse material to simplify the material location selection. Depending on the level of flexibility the warehouse manager needs, different material level related policies may be selected. The motivation for adopting a material location policy is reflected by the cost saving provided by the different location models compared to the current operations the industrial case study.

\section{Conclusion}

In this paper, the two-warehouse material location selection problem is introduced to assist manufacturers in measuring and minimizing the storage rental and transportation costs incurred by inefficiently allocating materials between owned and rented warehouses. The problem addresses the allocation of materials between two different warehouses; one is owned by a manufacturing company and the other is rented for excess inventory. The main objective of this problem is to simplify the material-location management by determining the shipment delivery and storage location for each material or item/pallet. To analyze the problem, four materiallocation policies with different selection criteria are proposed as decision support tools for a warehouse manager to determine item receiving/storage location. Four multi-stage network flow models are formulated to support location policy implementation. The models balance the use of 3PL warehouses by effectively utilizing the owned storage and minimizing the space rental and transportation costs that are incurred by storing fast moving items offsite, which results in repetitively transshipping items to the onsite production plant. 
The models are tested using data that is derived from a real industrial scenario and two different policy updating schemes. The results show that the cost saving for transportation and storage decreases as restrictions on item selection become more constraining. In addition, if demand changes seasonally, repeatedly updating the policies may not be beneficial since the set of items at each warehouse may change from one period to another leading to item reallocation cost incurred by moving items between warehouses.

The models developed provide a general guideline for how to allocate materials when a rented warehouse is used in conjunction with an owned warehouse. The models can be modified relatively easily to handle other specific cases, which may include different warehouse criteria such as material-location restriction (e.g. flammable material that can only be stored at a specific location) and scale-economies on warehouse space rental cost. The material-location selection problem proposed in this paper highlights the importance of this problem and its impact on overall warehouse operational cost. As a future research direction, in order to cope with the fluctuation in demand, the problem may be extended to incorporate a stochastic function to estimate future demand.

\section{Acknowledgement}

This research was supported in part by the National Science Foundation under Grant No. IIP0815195.

\section{References}

Bhunia, A.K., Maiti, M., 1998. A Two Warehouse Inventory Model for Deteriorating Items with a Linear Trend in Demand and Shortages. The Journal of the Operational Research Society 49, 287-292.

Bhunia, A.K., Pal, P., Chattopadhyay, S., Medya, B.K., 2011. An inventory model of twowarehouse system with variable demand dependent on instantaneous displayed stock and marketing decisions via hybrid RCGA. International Journal of Industrial Engineering Computations 2, 351-368.

Crama, Y., Moonen, L.S., Spieksma, F.C.R., Talloen, E., 2007. The tool switching problem revisited. European Journal of Operational Research 182, 952-957.

Chung, K.-J., Her, C.-C., Lin, S.-D., 2009. A two-warehouse inventory model with imperfect quality production processes. Computers \& Industrial Engineering 56, 193-197.

Goswami, A., Chaudhuri, K.S., 1992. An Economic Order Quantity Model for Items with Two Levels of Storage for a Linear Trend in Demand. The Journal of the Operational Research Society 43, 157-167.

Gu, J., Goetschalckx, M., McGinnis, L.F., 2007. Research on warehouse operation: A comprehensive review. European Journal of Operational Research 177, 1-21. 
Gu, J., Goetschalckx, M., McGinnis, L.F., 2010. Research on warehouse design and performance evaluation: A comprehensive review. European Journal of Operational Research 203, 539-549.

Hackman, S.T., Platzman, L.K., 1990. Near-Optimal Solution of Generalized Resource Allocation Problems with Large Capacities. Operations Research 38, 902-910.

Hartley, R.V., 1976. Operations Research: A Managerial Emphasis. Goodyear Publishing Company.

Hsieh, T.-P., Dye, C.-Y., Ouyang, L.-Y., 2008. Determining optimal lot size for a two-warehouse system with deterioration and shortages using net present value. European Journal of Operational Research 191, 182-192.

Jaggi, C., Verma, P., 2008. Joint optimization of price and order quantity with shortages for a two-warehouse system. TOP (Spain) 16, 195-213.

Langley Jr, C.J., Capgemini, 2014. 2014 Third-Party Logistics Study: The State of Logistics Outsourcing. University Park, PA.

Langley Jr, C.J., Capgemini, 2015. 2015 Third-Party Logistics Study: The State of Logistics Outsourcing. University Park, PA.

Lee, C.C., Hsu, S.-L., 2009. A two-warehouse production model for deteriorating inventory items with time-dependent demands. European Journal of Operational Research 194, 700-710.

Liang, Y., Zhou, F., 2011. A two-warehouse inventory model for deteriorating items under conditionally permissible delay in payment. Applied Mathematical Modelling 35, 2221-2231.

Maiti, A.K., Bhunia, A.K., Maiti, M., 2006. An application of real-coded genetic algorithm (RCGA) for mixed integer non-linear programming in two-storage multi-item inventory model with discount policy. Applied Mathematics and Computation 183, 903-915.

Matzliach, B., Tzur, M., 2000. Storage management of items in two levels of availability. European Journal of Operational Research 121, 363-379.

Mondal, B., Bhunia, A., Maiti, M., 2007. A Model on Two Storage Inventory System Under Stock Dependent Selling Rate Incorporating Marketing Decisions and Transportation Cost with Optimum Release Rule. Oxford Journal of Mathematical Sciences 23, 243.

Phillips, E.E., 2015. Collaborative Logistics Comes to the Warehouse, The Wall Street Journal, June 12, 2015.

Rao, K., Young, R.R., 1994. Global Supply Chains. International Journal of Physical Distribution \& Logistics Management, 24, 11-19.

Rong, M., Mahapatra, N.K., Maiti, M., 2008. A two warehouse inventory model for a deteriorating item with partially/fully backlogged shortage and fuzzy lead time. European Journal of Operational Research 189, 59-75. 
Rouwenhorst, B., Reuter, B., Stockrahm, V., van Houtum, G.J., Mantel, R.J., Zijm, W.H.M., 2000. Warehouse design and control: Framework and literature review. European Journal of Operational Research 122, 515-533.

Silver, E.A., Pyke, D.F., Peterson, R., 1998. Inventory Management and Production Planning and Scheduling. Wiley.

Tang, C.S., Denardo, E.V., 1988. Models Arising From A Flexible Manufacturing Machine, Part. Operations Research 36, 767.

Thangam, A., Uthayakumar, R., 2010. Optimal pricing and lot-sizing policy for a two-warehouse supply chain system with perishable items under partial trade credit financing. International Journal of Operational Research 10, 133-161.

Wutthisirisart, P., M.Y. Sir, and J.S. Noble, 2012. Analysis of a Complex Multi-Product Material Flow System of a Large Chemical Manufacturer, Proceedings of the 2012 The Industrial and Systems Engineering Research Conference, Orlando, FL, May 20-23 (6 pages on CD).

van den Berg, J.P., Sharp, G.P., Gademann, A.J.R.M., Pochet, Y., 1998. Forward-reserve allocation in a warehouse with unit-load replenishments. European Journal of Operational Research 111, 98-113.

Yang, H.-L., 2004. Two-warehouse inventory models for deteriorating items with shortages under inflation. European Journal of Operational Research 157, 344-356.

Yang, H.-L., 2006. Two-warehouse partial backlogging inventory models for deteriorating items under inflation. International Journal of Production Economics 103, 362-370.

Yu, J.P., 2007. A Joint Economic Production Lot Size Model for a Deteriorating Item with Decreasing Warehouse Rental Overtime, in: Computational Science and Its Applications ICCSA 2007, Gervasi, O., Gavrilova, M. (Eds.). Springer Berlin, pp. 818-831.

Zhou, Y.-W., 2003. A multi-warehouse inventory model for items with time-varying demand and shortages. Computers \& Operations Research 30, 2115-2134.

Zhou, Y.-W., Yang, S.-L., 2005. A two-warehouse inventory model for items with stock-leveldependent demand rate. International Journal of Production Economics 95, 215-228. 